\title{
Comparative genomic analysis of regulation of anaerobic respiration in ten genomes from three families of gamma-proteobacteria (Enterobacteriaceae, Pasteurellaceae, Vibrionaceae)
}

\author{
Dmitry A Ravcheev* $+1,2$, Anna V Gerasimova* ${ }^{*}$, Andrey A Mironov ${ }^{1,2,3}$ and \\ Mikhail S Gelfand $1,2,3$
}

Address: ${ }^{1}$ Lomonosov Moscow State University, Department of Bioengineering and Bioinformatics, Moscow, 119992, Russia, ${ }^{2}$ Institute for Information Transmission Problems, Moscow, 127994, Russia and ${ }^{3}$ State Scientific Center GosNIIGenetika, Moscow, 113545, Russia

Email: Dmitry A Ravcheev* - ravcheyev@iitp.ru; Anna V Gerasimova* - a_gerasimova@yahoo.com; Andrey A Mironov - mironov@ig-msk.ru; Mikhail S Gelfand - gelfand@iitp.ru

* Corresponding authors †Equal contributors

Published: 2I February 2007

BMC Genomics 2007, 8:54 doi:10.1/86/147|-2164-8-54

This article is available from: http://www.biomedcentral.com/I47I-2/64/8/54

(c) 2007 Ravcheev et al; licensee BioMed Central Ltd.

This is an Open Access article distributed under the terms of the Creative Commons Attribution License (http://creativecommons.org/licenses/by/2.0), which permits unrestricted use, distribution, and reproduction in any medium, provided the original work is properly cited.
Received: 16 August 2006

Accepted: 2I February 2007

\begin{abstract}
Background: Gamma-proteobacteria, such as Escherichia coli, can use a variety of respiratory substrates employing numerous aerobic and anaerobic respiratory systems controlled by multiple transcription regulators. Thus, in E. coli, global control of respiration is mediated by four transcription factors, Fnr, ArcA, NarL and NarP. However, in other Gamma-proteobacteria the composition of global respiration regulators may be different.
\end{abstract}

Results: In this study we applied a comparative genomic approach to the analysis of three global regulatory systems, Fnr, ArcA and NarP. These systems were studied in available genomes containing these three regulators, but lacking NarL. So, we considered several representatives of Pasteurellaceae, Vibrionaceae and Yersinia spp. As a result, we identified new regulon members, functioning in respiration, central metabolism (glycolysis, gluconeogenesis, pentose phosphate pathway, citrate cicle, metabolism of pyruvate and lactate), metabolism of carbohydrates and fatty acids, transcriptional regulation and transport, in particular: the ATP synthase operon atpIBEFHAGCD, $\mathrm{Na}^{+}$-exporting $\mathrm{NADH}$ dehydrogenase operon nqRABCDEF, the $\mathrm{D}$-amino acids dehydrogenase operon $d a d A X$. Using an extension of the comparative technique, we demonstrated taxon-specific changes in regulatory interactions and predicted taxon-specific regulatory cascades.

Conclusion: A comparative genomic technique was applied to the analysis of global regulation of respiration in ten gamma-proteobacterial genomes. Three structurally different but functionally related regulatory systems were described. A correlation between the regulon size and the position of a transcription factor in regulatory cascades was observed: regulators with larger regulons tend to occupy top positions in the cascades. On the other hand, there is no obvious link to differences in the species' lifestyles and metabolic capabilities. 


\section{Background}

Escherichia coli, the best-studied representative of gammaproteobacteria, can adapt to a wide variety of environmental conditions. One source of this capability is the presence of numerous aerobic and anaerobic respiratory systems. To adapt to different growth conditions, this bacterium alter the composition of their respiratory systems by changing the repertoire of substrate-specific dehydrogenases and terminal oxidoreductases. The concentration of each component is strictly regulated in order to optimize the respiratory chains according to the available substrates and the physiological needs of the cell.

In facultative anaerobe $E$. coli, regulation of respiration depends on the availability of electron acceptors, which are used in a specific order. Thus, molecular oxygen represses all other types of respiration and fermentation. Under anaerobiosis, nitrate, the most favorable electron acceptor in such conditions, represses other types of anaerobic respiration and fermentation. This control is effected by a variety of regulatory systems $[1,2]$.

The first level of regulation is implemented via the Fnr protein. Fnr is an oxygen-sensitive transcription factor. Oxygen is sensed by iron-sulfur clusters formed by the $\mathrm{N}$ terminal domain. Under anaerobic conditions, Fnr forms dimers that are capable of binding DNA, whereas in the presence of oxygen these clusters are reversibly destroyed and the dimers dissociate $[3,4]$. Thus, Fnr is active only under anaerobic conditions, when it activates genes necessary for the anaerobic metabolism and represses genes for the aerobic respiration $[2,5]$. In E. coli, Fnr is the top regulator of respiration, as it controls the expression of genes for other transcriptional factors $[6,7]$.

Another transcription factor regulating respiration is the ArcA protein. ArcA is a part of the ArcA-ArcB two-component system, where ArcB is an inner membrane sensor protein. ArcB is belived to sense the redox state of ubiquinones: in vitro, the activity of this protein depends on the redox status of a ubiquionone soluble analog [8,9]. In the absence of corresponding electron acceptors, ArcB phosphorylates ArcA, enabling it to bind DNA [10,11]. Thus, under the anaerobic conditions, ArcA regulates expression of genes for respiration and central metabolism, and probably controls the switch between the respiration and fermentation metabolisms [5,12-14].

The next level of regulation is provided by two homologous transcription factors, NarL and NarP. These proteins are activated in the presence of nitrate and nitrite by two homologous sensor kinases NarX and NarQ. The duplicated two-component system allows for the fine tuning of the nitrate and nitrite respiration system to a dynamic ratio of two alternative substrates. NarX and NarQ respond differentially to nitrate and nitrite. Thus, in this subsystem three levels of the response specificity may be distinguished: (i) interaction between sensor proteins and respiratory substrates, (ii) interaction between sensor proteins and transcription factors, and (iii) interaction between factors and their binding sites in DNA [15-18]. Upon activation, NarL and NarP activate genes for the nitrate and nitrate respiration and repress genes for other, less effective, pathways of anaerobic respiration [19-22].

Nevertheless, in some gamma-proteobacteria, only the single NarQ-NarP system was found [23], accompanied by reduction of the nitrate and nitrite respiratory system, and the presence of only the periplasmic respiratory system. So, in most gamma-proteobacteria the fine tuning of the system is not required and a single NarQ-NarP system is sufficient for the control of the nitrate and nitrite respiration [24].

Although the physiology and regulation of respiration in E. coli has been studied in considerable depth, the regulation in other organisms is poorly understood. Moreover, in other representatives of gamma-proteobacteria, for example, in Haemophilus influenzae, regulation of respiration looks to be quite different from E. coli $[25,26]$.

Previously, comparative genomic analyses were performed separately for Fnr [27], ArcA [28], and NarP [24] in a small number of microorganisms. Here we report the results of a comparative genomic analysis of the respiration regulation in multiple genomes belonging to several representatives of the three families of gamma-proteobacteria. Although the NarL-DNA interactions have been studied in experiment [29-32], the existing methods for prediction of transcription factor binding sites do not allow for the reliable identification of candidate NarL sites. Because of that, we analyzed the organisms containing only the NarP regulator. In such organisms, we studied three structurally different, but functionally related Fnr, ArcA and NarP systems.

\section{Results \\ Structure of the Fnr, ArcA and NarP regulogs}

The procedure described in "Methods" was applied to the analysis of regulation by Fnr, ArcA and NarP. All genes predicted to form regulogs (orthologous regulons) were classified according to their functions.

In comparison with previous studies, where single regulatory systems had been studied in several gamma-protoeobacterial genomes [24,27,33], here we predicted additional regulatory interactions. These predictions were made possible by the use of total pairwise comparison and detailed simultaneous analysis of multiple regulatory systems. Here we consider in detail only the relevant pre- 
dictions. A summary of these predictions is given in Table 1 , whereas more detailed data about site prediction, including information about operon structure changes, are shown in additional files 1 and 2 .

\section{Respiration}

One of the most significant results was the identification of conserved candidate sites upstream of the atpIBEF$H A G C D$ operon. This operon encodes all subunits of the ATP synthetase complex, the key component of the oxidative phosphorylation [34]. Experimental data about regulation of the atp operon in E. coli are conflicting. In particular, expression of the atp operon was claimed to be independent of Fnr or ArcA [35]. On the other hand, 1.5to 8 -fold increase of the expression level of various atp genes in the fnr mutant E. coli, as compared to the wildtype strain, was shown using a microarray assay [36]. Similarly, 1.9- to 14-fold increase of the expression level of various atp genes was shown in the arcA mutant strain [37]. Recently, candidate Fnr and ArcA sites were observed upstream of the atp operon in E. coli K-12 genome; these sites were conserved in many Enterobacteriaceae genomes [Tsiganova and Ravcheev, unpublished observation]. In the present study, candidate ArcA sites were observed upstream of the atp operon in both Yersinia spp., and Fnr sites were detected in all Vibrionaceae. Thus, in at least some gamma-proteobacteria, expression of the ATP synthetase genes is controlled by the global regulators of respiration.

Candidate regulatory sites were found upstream of the $n q r A B C D E F$ operon encoding $\mathrm{Na}^{+}$-exporting $\mathrm{NADH}$ dehydrogenase [38]. Candidate Fnr-binding sites are conserved in all studied genomes, whereas ArcA sites have been found in all Vibrionaceae and Pasteurellaceae, but not in the Yersinia spp. The regulation by NarP seems to be specific for the Pasteurellaceae. Orthologs for the nqr genes were not found in E. coli, but such orthologs were detected in Klebsiella pneumoniae and various Vibrionaceae and Pasteurellaceae [38-43]. On the other hand, E. coli has an $\mathrm{H}^{+-}$ exporting NADH dehydrogenase enzyme, encoded by the nuo operon, whose expression is regulated by the NarL and Fnr transcription factors $[44,45]$. No genes of the nuo operon demonstrate homology with the nqr genes. Orthologs of the nuo operon were found in the Yersinia genomes, but they were not preceded by candidate Fnr, ArcA or NarP binding sites. Thus, in the studied genomes, non-homologous displacement with a partial change of function leads to the sodium-dependent energetics used in conjunction with the proton-dependent one.

One more new regulog member is the $d a d A X$ operon. The first gene of this operon encodes the small subunit of respiratory D-amino acids dehydrogenase [46]. Candidate ArcA sites were detected in the Yersinia and Vibrionaceae genomes upstream of the dadAX operon. Thus, the use of $\mathrm{D}$-amino acids as electron donors in some genomes may be controlled by ArcA.

An interesting example of taxon-specific regulation was observed for duplicated operons for trimethylamine $\mathrm{N}$ oxide (TMAO) reductases and formate dehydrogenases. Two operons for TMAO reductases, torCAD and tor $Y Z$, were found in E. coli. $[47,48]$. The torCAD expression is known to be repressed by the NarL protein and activated by the transcriptional factor TorR $[49,50]$, whereas tor $Y Z$ is transcribed at a constant low level [47]. In the three Pasteurellaceae genomes, where the torCAD genes are absent, candidate sites for all three studied regulators were found upstream of the tor $Y Z$ operon. In the Vibrionaceae genomes, the tor $C A D$ transcription is likely controlled by Fnr, whereas the tor $Y Z$ expression seems to be regulated by NarP (see Table 1).

A similar situation was observed in E. coli for two formate dehydrogenase operons: the $f d n$ operon is known to be regulated by the Fnr, NarL, and NarP proteins $[51,52]$, whereas the expression of the fdo operon is constant [53]. Previously Fnr binding site was predicted upstream of the formate reductase operon in $Y$. pestis [27]. Careful analysis of the phylogenetical trees for the Fdn and Fdo proteins (additional file 3) revealed that both Yersinia spp. contain $f d o$ but lack $f d n$ genes. In both Yersinia spp. expression of the $f d o$ operon is regulated by all three studied regulators. Further, regulation was predicted for the $f d h D$ gene whose product is essential for the formation of the Fdn and Fdo protein complexes [54]. Accordingly, candidate regulatory sites upatream of $f d h D$ were found only in genomes containing the $f d o$ or $f d n$ operon.

\section{Central metabolism and fermentation}

Previously, respiration-dependent regulation of some genes involved in the central metabolism was studied in experiment $[5,55,56]$ and computationally $[27,28]$. Here, candidate regulatory sites were observed upstream of some more genes involved in the glycolysis, the gluconeogenesis, the pentose phosphate pathway, and the pyruvate and lactate metabolism: $s f c A, p p s A$, pckA, eno, $p g k, t a l B$ and aldB. Unexpectedly, in the Pasteurellaceae, candidate NarP binding sites were found upstream of operons for glycolysis/gluconeogenesis and citrate cycle enzymes, such as eno, pgk, mdh and sucABCD (see Table 1).

\section{Metabolism of carbohydrates}

Regulation of sugar metabolism genes by the three considered regulators has not been shown experimentally. Here, conserved candidate sites for Fnr, ArcA or NarP were found upstream of some operons involved in the metabolism of various sugars. This is not surprising: indeed, the sugar metabolism is closely related to the central metabo- 
Table I: Predicted regulatory interactions. For genome abbreviations see "Methods".

\begin{tabular}{|c|c|c|c|c|c|c|c|c|c|c|}
\hline \multirow[t]{2}{*}{ Operon } & \multicolumn{10}{|c|}{ Genome } \\
\hline & YP & YE & PM & AA & HI & HD & Vv & VP & vc & VF \\
\hline \multicolumn{11}{|c|}{ Respiratory enzymes } \\
\hline atpIBEFHAGDC* & $-A-$ & fAn & fan & -an & --- & $f--$ & F-- & Fa- & F-n & F-- \\
\hline$c y d A B$ & Fan & Fa- & FA- & $\mathrm{F}-\mathrm{N}$ & FAN & FAN & FAN & FAN & FAN & FAN \\
\hline napFDAGHBC* & FAN & FAN & $\mathrm{F}-\mathrm{N}$ & $\mathrm{F}-\mathrm{N}$ & $\mathrm{FaN}$ & $\mathrm{FaN}$ & FAN & FAN & FAN & FAN \\
\hline ccmABCDEFGH & $f-N$ & $--\mathrm{N}$ & $\mathrm{F}-\mathrm{N}$ & $\mathrm{FaN}$ & $\mathrm{F}-\mathrm{N}$ & $\mathrm{FaN}$ & $\mathrm{FaN}$ & $\mathrm{FaN}$ & $--\mathrm{N}$ & $\mathrm{F}-\mathrm{N}$ \\
\hline nrfABCDEXFG* & 0 & 0 & $\mathrm{~F}-\mathrm{N}$ & $\mathrm{F}-\mathrm{N}$ & $\mathrm{FaN}$ & $\mathrm{FaN}$ & $\mathrm{FaN}$ & $\mathrm{F}-\mathrm{N}$ & 0 & $\mathrm{FaN}$ \\
\hline nirBDC-cysG & $\mathrm{F}-\mathrm{N}$ & $\mathrm{F}-\mathrm{N}$ & 0 & 0 & 0 & 0 & $\mathrm{~F}-\mathrm{N}$ & $\mathrm{F}-\mathrm{N}$ & 0 & $\mathrm{~F}-\mathrm{N}$ \\
\hline$d m s A B C$ & $f-n$ & 0 & $\mathrm{~F}-\mathrm{N}$ & $\mathrm{F}-\mathrm{N}$ & $\mathrm{F}-\mathrm{N}$ & 0 & 0 & fa- & 0 & fan \\
\hline $\operatorname{tor} Y Z$ & 0 & $--n$ & 0 & FAN & FAN & FAN & 0 & $--\mathrm{N}$ & $--\mathrm{N}$ & $--\mathrm{N}$ \\
\hline torCAD* & 0 & 0 & fan & 0 & 0 & 0 & Fa- & $\mathrm{F}-\mathrm{n}$ & Fa- & $F-n$ \\
\hline frdABCD & $-A-$ & $\mathrm{fA}-$ & FAN & FAN & FAN & FAN & $\mathrm{faN}$ & $--N$ & $--\mathrm{N}$ & $\mathrm{faN}$ \\
\hline fdoGHI & FAN & FAN & FAn & FAn & $-A-$ & 0 & 0 & 0 & 0 & 0 \\
\hline $\mathrm{fdnGHI}$ & 0 & 0 & & & & 0 & 0 & 0 & 0 & 0 \\
\hline$f d h D$ & $-A N$ & $-A N$ & $\mathrm{fAn}$ & $\mathrm{fAn}$ & $-A-$ & $-A-$ & 0 & --- & 0 & 0 \\
\hline$n q r A B C D E F$ & $\mathrm{Fa}-$ & F-- & FAN & FAN & FA- & FAN & FA- & FA- & FA- & FAn \\
\hline ndh & FA- & FAn & 0 & $f A-$ & $-A n$ & $\mathrm{fAn}$ & F-- & F-- & F-- & F-- \\
\hline$g \mid p A B C$ & F-- & Fa- & F-- & --- & F-- & Fa- & Fa- & 0 & F-- & F-n \\
\hline$g \mid p D$ & F-- & F-- & 0 & $f--$ & 0 & 0 & --- & --- & $f--$ & fa- \\
\hline $\operatorname{dad} A X$ & $-A-$ & $-A-$ & 0 & 0 & 0 & 0 & fA- & $-A n$ & $-A n$ & 0 \\
\hline \multicolumn{11}{|c|}{ Molibdenum cofactor synthesis } \\
\hline moaABCDE* & Fa- & F-- & F-- & $\mathrm{F}-\mathrm{N}$ & $\mathrm{F}-\mathrm{N}$ & $\mathrm{FaN}$ & $--\mathrm{N}$ & $--\mathrm{N}$ & $--\mathrm{N}$ & --- \\
\hline moeAB & --- & $f--$ & F-- & FA- & FA- & FA- & --- & --- & --- & $-\mathrm{a}-$ \\
\hline \multicolumn{11}{|c|}{ Central metabolism and fermentation } \\
\hline pgk & --- & --- & $--\mathrm{N}$ & --- & $\mathrm{faN}$ & $-\mathrm{aN}$ & F-- & F-- & F-- & F-- \\
\hline eno & --- & $-a-$ & $\mathrm{F}-\mathrm{N}$ & $\mathrm{FaN}$ & $\mathrm{F}-\mathrm{N}$ & F- & --- & $--n$ & --- & --- \\
\hline aldB & 0 & 0 & 0 & 0 & 0 & $\mathbf{0}$ & FA- & FA- & FA- & FA- \\
\hline adhE & fa- & --- & $f-n$ & $f-n$ & 0 & --- & FAN & FAN & FAN & FAN \\
\hline pdhR-aceEF-IpdA* & FA- & FA- & $-A-$ & $-A n$ & $-A-$ & $-A n$ & FA- & $\mathrm{F}-\mathrm{N}$ & FAN & FAN \\
\hline pflB & $--\mathrm{N}$ & $--\mathrm{N}$ & $-A N$ & $-A N$ & $-A-$ & $f-N$ & $-A N$ & $--\mathrm{N}$ & $f A-$ & $-A N$ \\
\hline yfiD & $\mathrm{Fa}-$ & F-- & FA- & FA- & FA- & $-A n$ & $\mathrm{~F}-\mathrm{N}$ & FAN & FAN & FAN \\
\hline mdh & $-A-$ & $f A-$ & $f-N$ & $-\mathrm{aN}$ & $f-N$ & $-\mathrm{aN}$ & FA- & FA- & FA- & --- \\
\hline pckA & --- & --- & $--n$ & $-A-$ & fAn & $f A-$ & $-A-$ & $-A n$ & $-A-$ & fAn \\
\hline ppsA & F-- & F-- & 0 & 0 & 0 & 0 & $-A-$ & $\mathrm{fA}-$ & --- & $-A-$ \\
\hline aspA & $f--$ & $-a-$ & $-A-$ & $f--$ & $-A-$ & $-A n$ & $--\mathrm{N}$ & $--\mathrm{N}$ & 0 & $\mathrm{faN}$ \\
\hline$s f c A$ & $--\mathrm{N}$ & $\mathrm{faN}$ & 0 & --- & 0 & 0 & F-- & F-- & F-- & $F-n$ \\
\hline sdhCDAB & $-A-$ & $-A-$ & 0 & 0 & 0 & 0 & $-A-$ & $f A-$ & $f A-$ & $-A-$ \\
\hline gltA & $-A-$ & $-A-$ & -an & 0 & 0 & 0 & $-A-$ & $f A-$ & $f A-$ & $-A-$ \\
\hline fumC & $f--$ & --- & $-\mathrm{aN}$ & $--\mathrm{N}$ & $--N$ & $f--$ & 0 & $-a-$ & fa- & 0 \\
\hline SucABCD* & --- & --- & $-A N$ & $-A-$ & fAN & fAN & --- & --- & --- & $-a-$ \\
\hline IdhA & --- & f-- & 0 & --- & $-a-$ & 0 & $-a-$ & $--\mathrm{N}$ & $f-N$ & $-\mathrm{aN}$ \\
\hline talB & f-- & --- & $-\mathrm{aN}$ & 0 & $f-N$ & $f-N$ & $-a-$ & $f--$ & --- & --- \\
\hline
\end{tabular}


Table I: Predicted regulatory interactions. For genome abbreviations see "Methods". (Continued)

\begin{tabular}{|c|c|c|c|c|c|c|c|c|c|c|}
\hline \multicolumn{11}{|c|}{ Metabolism of carbohydrates } \\
\hline$m t \mid A D R$ & fA- & $-A-$ & --- & 0 & 0 & 0 & F-- & Fa- & F-- & 0 \\
\hline nagBACD* & --- & --- & fa- & --- & --- & $--n$ & F-- & F-- & F-- & F-n \\
\hline ptsHl-crr & $--n$ & --- & $-A-$ & $-A n$ & $-A-$ & $f A-$ & --- & $--n$ & $-a-$ & $--n$ \\
\hline deoCABD* & $f--$ & $-a-$ & --- & --- & $f--$ & $f--$ & $--\mathrm{N}$ & $--\mathrm{N}$ & --- & $--N$ \\
\hline malQ-glgBXCAP* & Fa- & F-- & $\mathrm{F}-\mathrm{N}$ & $\mathrm{F}-\mathrm{N}$ & $\mathrm{F}-\mathrm{N}$ & 0 & -an & $f--$ & fa- & fan \\
\hline
\end{tabular}

Fatty acids metabolism

\begin{tabular}{|c|c|c|c|c|c|c|c|c|c|c|}
\hline fadl] & $-A-$ & $-A-$ & 0 & 0 & 0 & 0 & FA- & FA- & F-- & FA- \\
\hline fadBA & FAn & FA- & 0 & 0 & 0 & 0 & $-A-$ & fA- & $-A-$ & fA- \\
\hline$f a d D$ & $f A-$ & $-A n$ & --- & $-a-$ & -an & f-- & $-A-$ & $-A-$ & $-A-$ & $-A-$ \\
\hline$a c p P-f a b F^{*}$ & $-A-$ & $-A-$ & fan & --- & --- & --- & F-- & F-- & F-- & --- \\
\hline
\end{tabular}

Oxygen stress response

\begin{tabular}{|c|c|c|c|c|c|c|c|c|c|c|}
\hline $\operatorname{sod} A$ & $-A-$ & $-A-$ & FA- & FA- & FAn & FA- & 0 & 0 & 0 & 0 \\
\hline \multicolumn{11}{|c|}{ Nucleotide reductases } \\
\hline$n r d D G$ & F-- & F-- & $f--$ & -an & $f--$ & 0 & F-- & Fa- & F-- & F-- \\
\hline $\operatorname{nrdAB}$ & $--n$ & --- & $\mathrm{F}-\mathrm{n}$ & F-- & Fa- & --- & --- & --- & $f--$ & $f--$ \\
\hline
\end{tabular}

\begin{tabular}{|c|c|c|c|c|c|c|c|c|c|c|}
\hline \multicolumn{11}{|c|}{ Transport } \\
\hline focA & FAN & FAN & FA- & FA- & FA- & FA- & --- & $f--$ & --- & fa- \\
\hline$d c u B$ & $-A-$ & fA- & $\mathrm{F}-\mathrm{N}$ & $\mathrm{F}-\mathrm{N}$ & 0 & $\mathrm{~F}-\mathrm{N}$ & $-a-$ & --- & $f--$ & fan \\
\hline $\operatorname{dcuA}$ & $-A-$ & $f A-$ & $--N$ & $\mathrm{f}-\mathrm{N}$ & $f-N$ & $-a-$ & --- & $--n$ & --- & $--n$ \\
\hline dcuC & 0 & f-- & $-a-$ & $-a-$ & 0 & 0 & Fa- & F-- & F-- & Fa- \\
\hline$g l t P$ & $-A n$ & $f A-$ & 0 & 0 & 0 & 0 & fAn & $-A-$ & $-A-$ & fAn \\
\hline$g l p F K$ & $-A n$ & $-A-$ & $f--$ & 0 & -an & fa- & $-A-$ & $-A n$ & --- & $-A n$ \\
\hline gnt $X Y$ & --- & --- & FA- & F-- & FA- & FA- & --- & --- & --- & $--n$ \\
\hline fadL & FA- & FA- & --- & $-a-$ & $f--$ & $-a-$ & FA- & $-A-$ & FA- & FA- \\
\hline$f e o A B$ & --- & $f--$ & 0 & 0 & 0 & 0 & FAN & FAN & $-A N$ & FA- \\
\hline \multicolumn{11}{|c|}{ Peptidase T } \\
\hline рерT & F-- & F-- & F-- & F-- & F-- & 0 & F-- & $\mathrm{Fa}-$ & F-- & Fan \\
\hline \multicolumn{11}{|c|}{ Transcription regulators } \\
\hline fnr & F-- & F-- & FAN & FAN & FAN & FA- & Fa- & Fa- & F-- & F-- \\
\hline $\operatorname{arc} A$ & FA- & FA- & f-- & --- & $f-n$ & $-a-$ & FA- & FA- & FA- & FA- \\
\hline$n a r Q P$ & $-a-$ & $--n$ & $f--$ & $--n$ & fan & $-a-$ & FAN & FAN & FAN & FAN \\
\hline dusB-fis & $-a-$ & --- & FA- & $-A-$ & F-- & FA- & --- & --- & --- & f-- \\
\hline$c p x R A$ & --- & --- & FA- & FA- & FA- & FAn & --- & --- & --- & $-a-$ \\
\hline $\operatorname{oxy} R$ & --- & --- & $-A-$ & $-A-$ & $-A-$ & $f A-$ & --- & $f--$ & --- & $-a-$ \\
\hline fur & --- & --- & F-- & Fa- & F-- & F-- & $-A-$ & $-A-$ & $-A-$ & $-A n$ \\
\hline
\end{tabular}

Candidate sites are shown by letters: F - Fnr sites; A - ArcA sites, N-NarP sites; conserved sites are shown by capital letters, non-conserved ones by lower-case letters (for details see "Methods"). Absence of sites is shown by dashes. Absent genes are shown by zeros. Cases when the operon structure is not conserved are denoted by asterics. 
lism and sugars provide substrates for the energy production [57]. In particular, candidate sites were observed upstream of the operons ptsHI-crr and mtlADR (glucoseand mannitol-specific phosphotransferase systems, respectively [58]), deoCABD (degradation of pyrimidine deoxynucleosydes via deoxyribose-phosphates to acetaldehyde and glycerol-3-phosphate [59]), nagB (glucosamine-6-phosphate deaminase [60]), gntXY (gluconate transport system [61]), malQ (amylomaltase [62]), and glgBXCAP (glycogen biosynthesis and catabolism [63]).

An unusual situation was observed for the glg genes. According to criteria described in "Methods", these genes were assigned to a single operon in the Yersinia spp. In the Pasteurellaceae, the glg genes are preceded by the malQ gene that belongs to the candidate malQ-glgBXCAP operon. In both Yersinia spp., candidate Fnr sites were found upstream of the $\lg B$ gene, whereas in the Pasteurellaceae, Fnr and NarP sites were found upstream of the malQ gene. Site conservation despite operon reorganization shows that the regulation of the glg genes by respiratory factors is important for the bacterial cell.

However, the degree of conservation of candidate sites for the carbohydrate metabolism genes is relatively low compared to genes from other groups, the observed sites are often taxon-specific, and there are almost no cases of double or triple combinations. This also is not surprising, since regulation of carbohydrate transport and catabolism is extremely flexible and fast-evolving (O.Laikova, personal communication). On the other hand, each individual predictions should be considered as preliminary.

\section{Fatty acids metabolism}

The regulation of operons involved in the fatty acids metabolism was not described previously, although there were some indirect indications to the existence of such regulation $[27,64]$. Some of these operons have conserved binding sites and thus are likely to be regulated.

The homologous fabBA and fadIJ operons encode protein complexes for beta-oxidation of fatty acids. The FadBA protein complex is used in the fatty acids degradation in both aerobic and anaerobic conditions, whereas FadIJ is used predominantly during anaerobiosis $[64,65]$. Previously an effect of the arcA mutation on the fadBA operon expression was observed, although direct regulation was not shown [13]. Here, conserved candidate sites for Fnr and/or ArcA were found upstream of both these operons (Table 1).

The regulation was also predicted for the $f a d D, a c p P-f a b F$, and $\mathrm{fadL}$ operons involved in the fatty acids metabolism and transport.
There are two possible explanations for the regulation of the fatty acids metabolism by the respiratory regulators. First, the fatty acids metabolism is closely related to the central metabolism, for example, through acetyl-CoA $[66,67]$. Second, different enzymes for the fatty acids oxydation are preferred under aerobic and anaerobic conditions [64].

\section{Nucleotide reductases}

Fnr is known to activate the $n r d D G$ operon in E. coli under anaerobiosis, whereas expression of one more operon encoding nucleotide reductase, $n r d A B$, is uneffected by the Fnr protein in E. coli [68]. This situation is conserved in the Yersinia spp. and the Vibrionaceae. In contrast, in the Pasteurellaceae, candidate Fnr sites were found upstream of the $n r d A B$ operon. However, in $H$. ducreyi, where the $n r d D G$ operon is absent, no candidate sites were found upstream of $n r d A B$. So, the overall picture seems to be that at least one nucleotide reductase operon must be transcribed constantly.

\section{Transport}

Previously, regulation by at least one of the studied regulators was shown experimentally for a number of $E$. coli transporter operons, see references in Table 1 . Here, we identified additional transporters in the studied regulogs and demonstrated changes in the regulatory interactions.

Previously regulation of dicarboxylate transporters genes $d c u A, d c u B$ and $d c u C$ was shown for E.coli (see references in Table 1). However, in other gamma-proteobacteria the regulation of these genes may be different. Thus, the regulation of the $d c u A$ and $d c u B$ genes is typical for the Yersinia spp. and Pasteurellaceae, whereas in Vibrionaceae the regulation was observed for $d c u C$.

\section{Regulators of transcription}

Prediction of regulation of genes encoding different transcription factors seems to be one of the most interesting results of this study. Previously, the fnr, $\operatorname{arcA}$, narP, and nar $Q$ genes were shown to be regulated by respiratory regulators in E. coli (see references in Table 1).

Fis is one of the most abundant DNA architectural proteins. It regulates supercoiling of bacterial DNA [69]. Experimentally it was shown that, in E. coli, Fis together with Fnr and/or ArcA regulates expression of the $\operatorname{nrf}[70]$, nir [71], ndh [72], adhE [73], yfiD [74], sdhCDAB-sucABCD [75], acnB [76], and narK [77] operons. In E. coli, the fis gene is cotranscribed with $d u s B[78]$ and the structure of the dusB-fis locus is conserved in all studied genomes. In the Pasteurellaceae, candidate Fnr and ArcA sites were found upstream of the $d u s B$ gene. Thus, in these genomes fis transcription is likely to be controlled by the respiratory regulators. Since Fis participates in the control of expres- 
sion of respiration genes, it is possible that Fnr and ArcA regulate expression of the fis gene to optimize the transcription control of these genes.

The $c p x R A$ operon encodes a two-component regulatory system involved in the environmental stress response [79]. Some data point to cross-interactions between the CpxR-CpxA and ArcA-ArcB systems in E. coli [80]. In the Pasteurellaceae, conserved Fnr and ArcA sites were detected upstream of the $c p x$ operon.

OxyR is the transcriptional factor for the oxidative stress response [81]. In all Pasteurellaceae, candidate ArcA sites were observed upstream of $o x y R$ gene. Since ArcA is active as a transcription factor only in the absence of the oxygen, it may be possible that in these conditions it represses the transcription of the unneeded oxygen sensor gene oxyR. However, the regulatory logic in this case is not absolutely clear.

In the Pasteurellaceae, conserved Fnr sites were found upstrean of the fur gene, whereas in the Vibrionaceae, the fur gene has candidate sites for ArcA. The observation that the Fur protein, ferric uptake regulator [82], is controlled by the respiratory regulators is not unexpected, because iron is an obligatory component of most respiratory complexes [2] and the transcriptional factor Fnr itself [83].

\section{Other members of regulogs}

In addition to the regulogs members described above, some genes were assigned to regulogs based on the formal criterion (see "Methods"), although their relevance to the respiration and central metabolism is not obvious. These genes and the candidate Fnr, ArcA, and NarP sites are shown in additional files 4 and 5 . Although in the absence of a functional link, these predictions are somewhat weaker then the ones in the previous sections, we belive that they still warrant experimental verification.

\section{Divergons and false-positive predictions}

In some cases we found sites in intergenic regions between two genes forming divergons. In such cases it is not immediately clear, which of the two divergently transcribed operons is regulated. These divergent operon pairs are $f a d R / n h a B-d s b B$ in most studied genomes, $\gamma f i C / b r n Q$, torD/torR, and yhdWXYZ/VV12702 in the Vibrionaceae, and $f k p A / s l y X$ in the Yersinia spp. and the Pasteurellaceae. The data about candidate sites upstream of divergent genes are present in additional file 5.

In other cases candidate regulog members in divergons were dismissed, as functional analysis made it clear which of two divergent operons was regulated. This category includes the argR, ung, nfo and potABCD operons (additional file 6).

\section{Discussion \\ Composition of regulogs in different families}

The above analysis shows that regulation often differs between bacterial families. To assess the relative role of each studied regulator in different families, we calculated the number of genes and operons belonging to each regulog in each studied family. As expected, the composition of regulogs turned out to be quite diverse.

For example, in the Yersinia spp., the NarP regulog is significantly smaller than in other studied families (Figure 1a). It is not surprising, given that in these bacteria the nitrate- and nitrite-respiration system is strongly reduced, and only nitrate, but not nitrite, is used as an electron acceptor [24]. Accordingly, in these organisms, the nitrate respiration plays a less prominent role, and the nitratesensing system also is less important as compared to other studied genomes.

In contrast, in Pasteurellaceae, the NarP regulog is somewhat enlarged in comparison with the other two taxons. One more feature of this group is the increased overlap between regulogs. For example, conserved sites for both Fnr and NarP regulators were found upstream of 13 operons containing 53 genes (Figure 1b).

In the Vibrionaceae, the ArcA regulog is extended as compared to the other groups. In this family, conserved ArcA sites were found upstream of 47 operons containing 99 genes (Figure 1c).

\section{Regulatory cascades}

Group-specific regulatory cascades were predicted based on candidate sites upstream of the $f n r, \operatorname{arc} A$, and narP genes.

In E. coli, such cascades were analyzed experimentally (Figure 2a) $[6,7,84]$. There, the Fnr protein is the main regulator of the respiration that controls expression of genes for other regulators. Fnr represses transcription of the narXL operon [6] and regulates expression of the $\operatorname{arcA}$ gene [7]. Moreover, the $f n r$ gene is autoregulated [6]. The $\operatorname{arcA}$ gene was predicted to be positively autoregulated [28]. The regulators of the nitrate and nitrate respiration, in turn, form a complicated regulatory network, where NarL activates expression of the narXL, narP and narQ operons, and NarP, in turn, activates the narXL transcription [84].

However, this situation is not conserved in the genomes of other gamma-proteobacteria. In the Yersinia spp., Fnr apparently regulates the $\operatorname{arcA}$ expression and both $\mathrm{fnr}$ and $\operatorname{arcA}$ genes are autoregulated (Figure $2 \mathrm{~b}$ ). No regulatory sites were found upstream of the narP and narX genes. Thus, in the Yersinia spp., Fnr is the main regulator of res- 
(a)

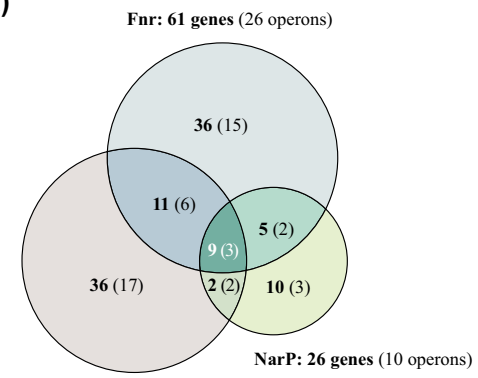

ArcA: 58 genes (28 operons) (b)

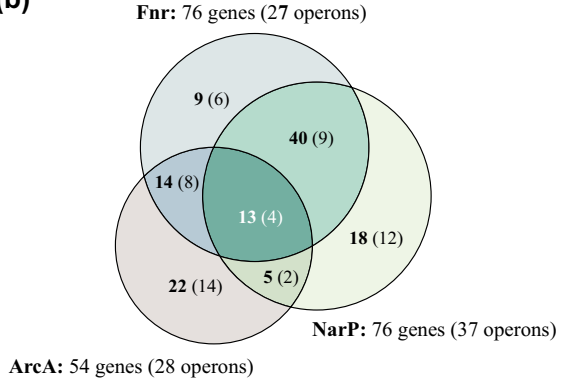

(c)

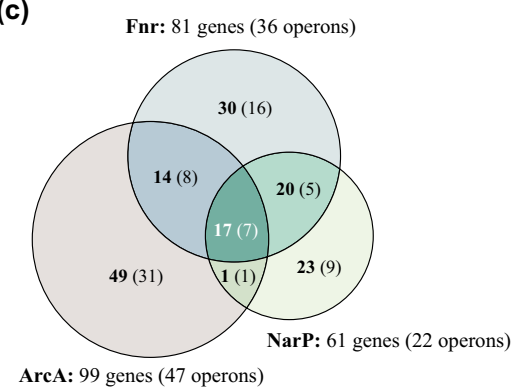

Figure I

Regulogs composition in three families. (a) Enterobacteriaceae (Yersinia spp.); (b) Pasteurellaceae; (c) Vibrionaceae. The numbers of genes and operons in parentheses predicted to belong to the regulogs are shown.

(a)

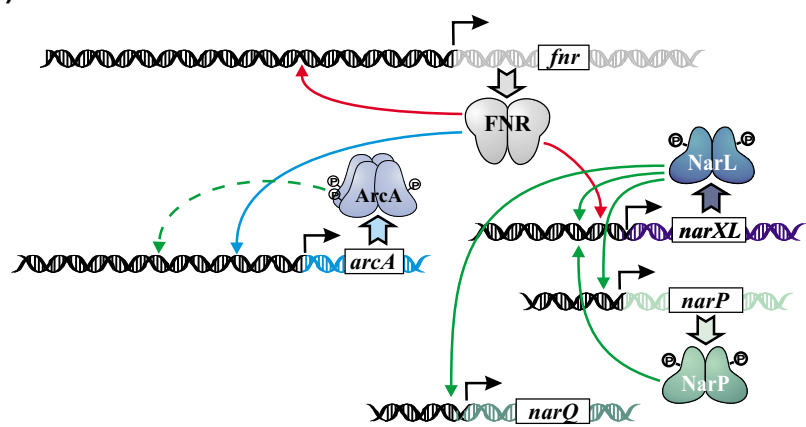

(c)

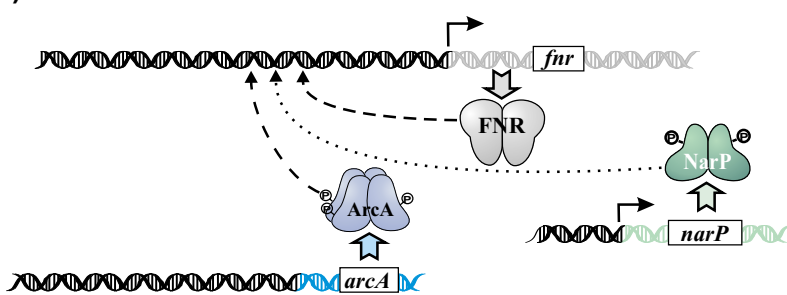

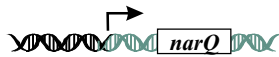

(b)

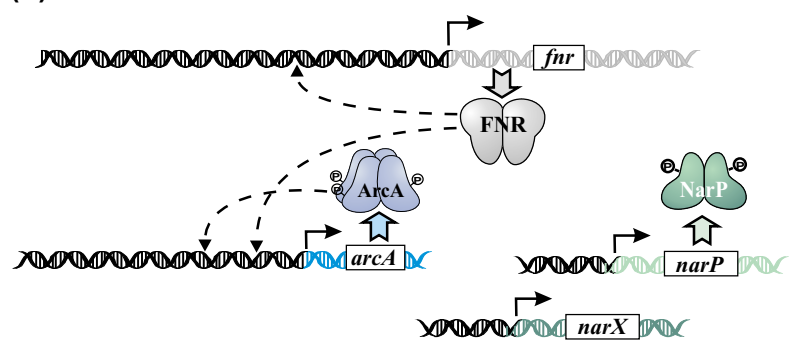

(d)

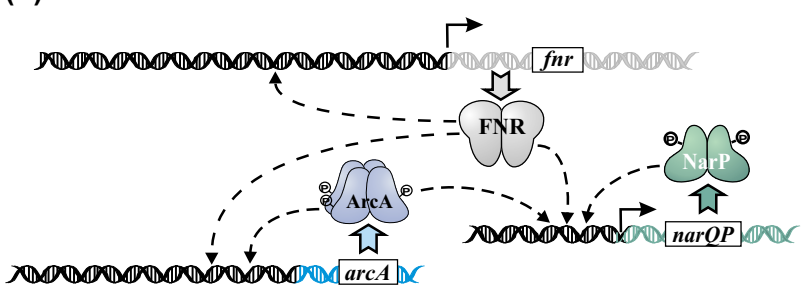

\section{Figure 2}

Respiration regulatory cascades in gamma-proteobacteria. (a) E. coli; (b) Yersinia spp.; (c) Pasteurellaceae; (d) Vibrionaceae. Experimentally determined regulation is shown by continuous arrows: green, activation; red, repression; blue, ambivalent regulation. Predicted regulation is shown by broken arrows: green, activation; black, type of regulation is not determined. Dotted arrows in (c): sites were not found in $H$. ducreyi. 
piration, similarly to E. coli. However, unlike the situation in the latter, in the Yersinia spp., the nitrate- and nitriteresponsive regulatory system does not participate in the regulatory cascades.

Even more remarkable changes in the regulatory cascades were observed in the Pasteurellaceae. In most of these genomes, candidate sites for Fnr, ArcA and NarP were found upstream of the $f n r$ gene (Figure 2c), whereas no conserved regulatory sites were observed for the $\operatorname{arcA}$ and narP genes. This suggests that in this family the role of Fnr in the regulatory cascades decreases in comparison with $E$. coli. Minor differences were seen in $H$. ducreyi, where no NarP sites were found upstream of the $f n r$ gene (Figure 2c).

In the Vibrionaceae, autoregulation for all regulator genes, fnr, arcA and narP, was observed. The ArcA protein also seems to regulate the narP gene, whereas Fnr controls the expression of the $\operatorname{arcA}$ and narP genes (Figure 2d). Thus, in these organisms, Fnr again is the main respiration regulator, but the role of ArcA in the regulatory cascades is increased as compared to E. coli.

Thus, the E.coli pattern of regulatory cascades is not conserved in other gamma-proteobacteria, and the relative role of each regulator in the regulatory cascades differs between families. When more genomes become available, it might be possible to describe the evolution of this regulatory system in more detail.

\section{Family-specific regulatory interactions}

In addition to differences in the regulatory cacades, there are major differences in the functional content of the respiration regulogs. These data are summarized in Figures 3, 4,5 .

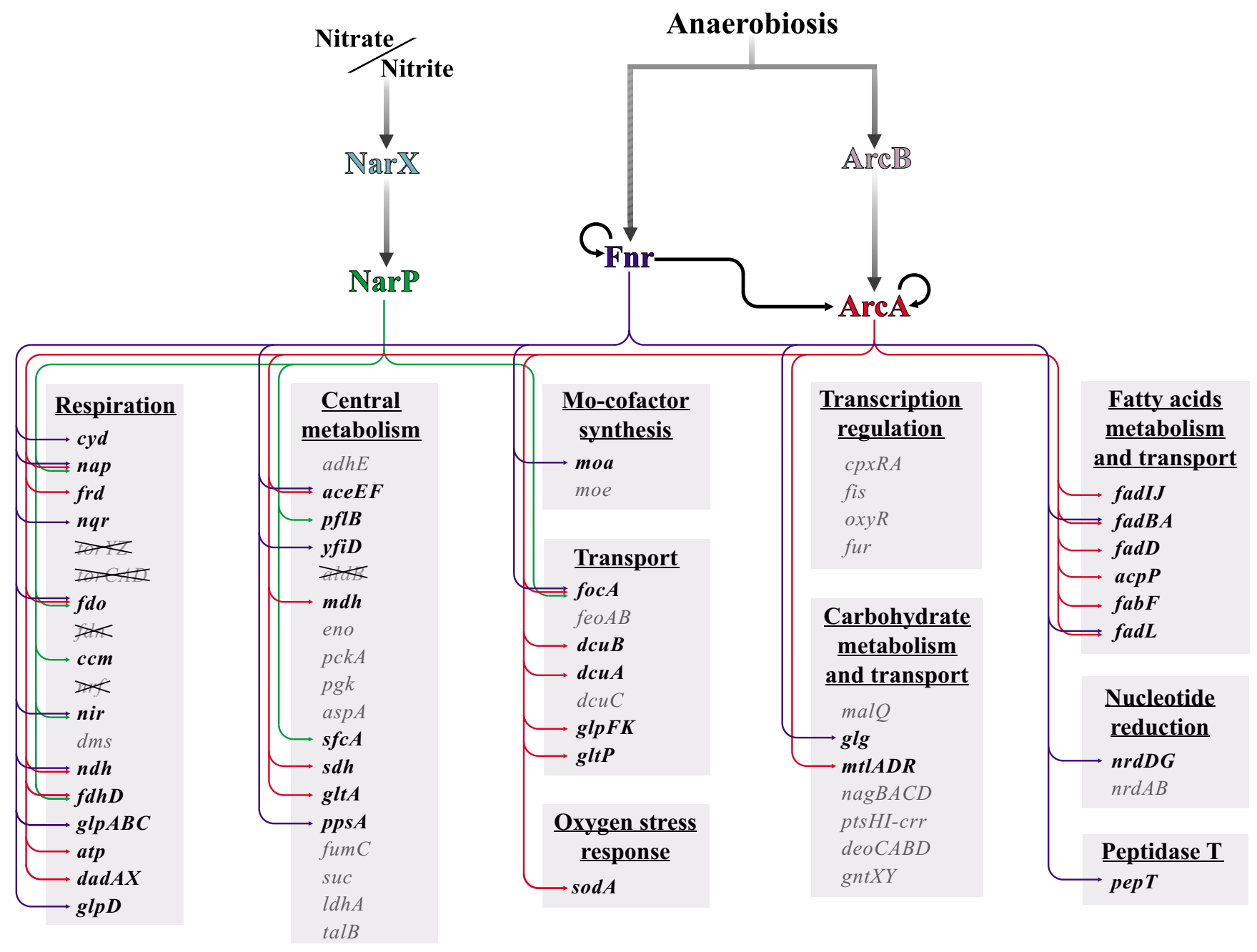

Figure 3

Regulatory interactions in Yersinia spp. Regulatory cascades are shown by thick black arrows. Predicted transcriptional regulation is shown by thin arrows, blue for Fnr, red for ArcA, and green for NarP. 


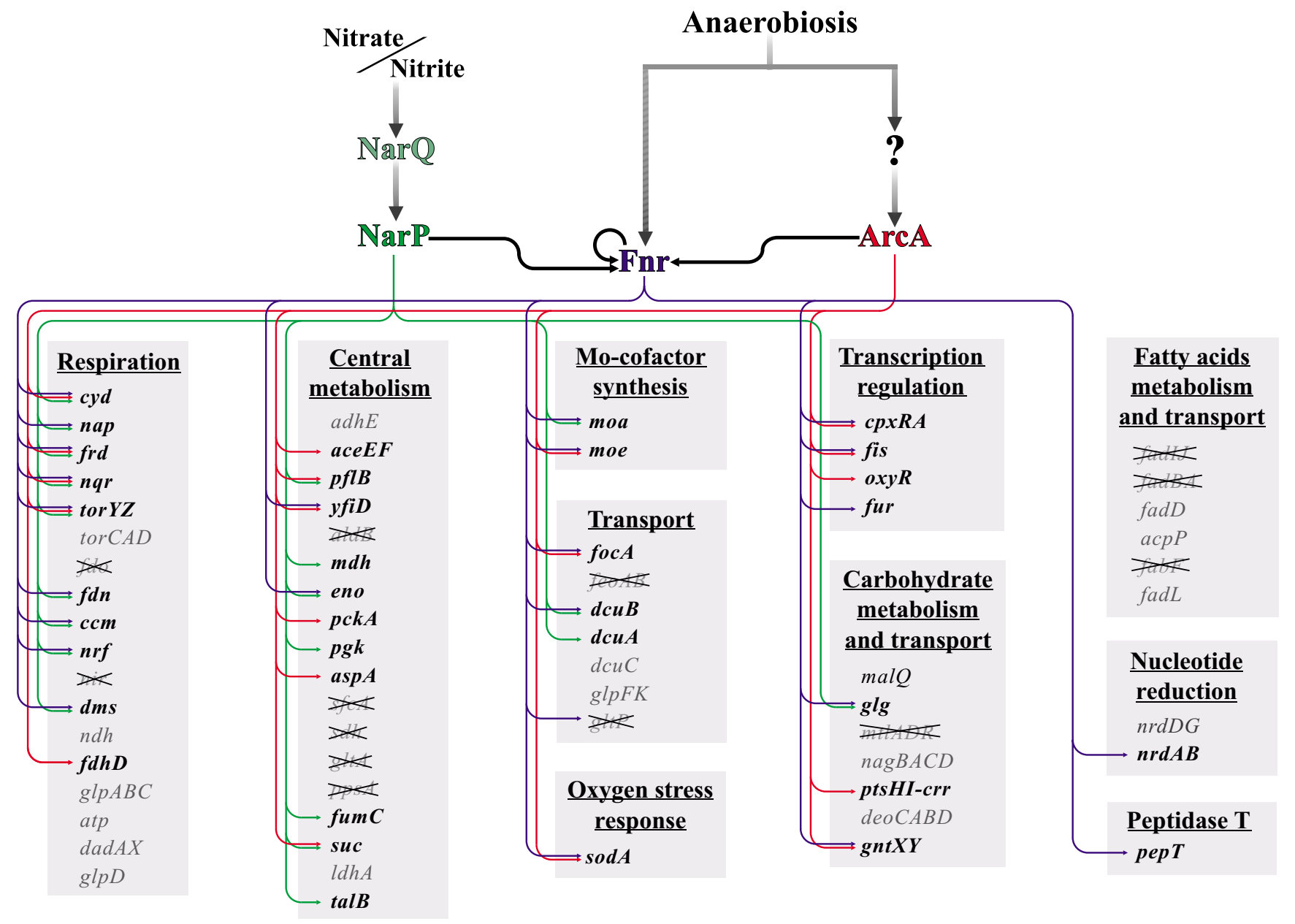

Figure 4

Regulatory interactions in Pasteurellaceae. Notation as in Figure 3.

\section{Enterobacteriaceae (Yersinia spp.)}

Two genomes of the Yersinia spp. were selected for this study because of the presence of a single regulator of the nitrate and nitrite respiration regulator NarP. These bacteria demonstrate a number of features that distinguish them from both $E$. coli and the two other studied families (Figure 3).

Most of these features relate to the nitrate and nitrite respiration. First of all, regulation is mediated by the unusual pair NarX-NarP, in contrast to other bacteria that have the pair NarQ-NarP (for details see below).

Another feature of the Yersinia spp. regulation is simplification of the regulatory cascades (see above). In comparison with E. coli, only the Fnr-ArcA cascade is conserved, whereas nitrate and nitrite responsive proteins seem to be excluded from cascades. This has an effect on the NarP regulog: in the respiration subsystem, candidate sites were found only upstream of genes essential for the nitrate res- piration using formate as an electron donor ( $\mathrm{nap}, \mathrm{ccm}, \mathrm{fdo}$, $f d h D)$, and upstream of the nir operon, whose products protect the cell from the toxic nitrite.

On the contrary, the Fnr and ArcA regulogs seemed to be quite similar to the corresponding regulogs in other studied genomes.

\section{Pasteurellaceae}

These bacteria demonstrate considerable changes in the regulatory cascade structure (see above). In the organisms from this group, Fnr loses the role of the main regulator.

A conspicious feature is the absence of orthologs for the ArcA-activating sensor ArcB (data not shown). Such situation was observed in another gamma-proteobacterium, Shewanella oneidensis MR-1 [85]. It is possible that the role of the ArcA-activating protein is played by CpxA that is homologous to ArcB. Regulation of the $c p x R A$ operon by Fnr and ArcA also points to this possibility. 


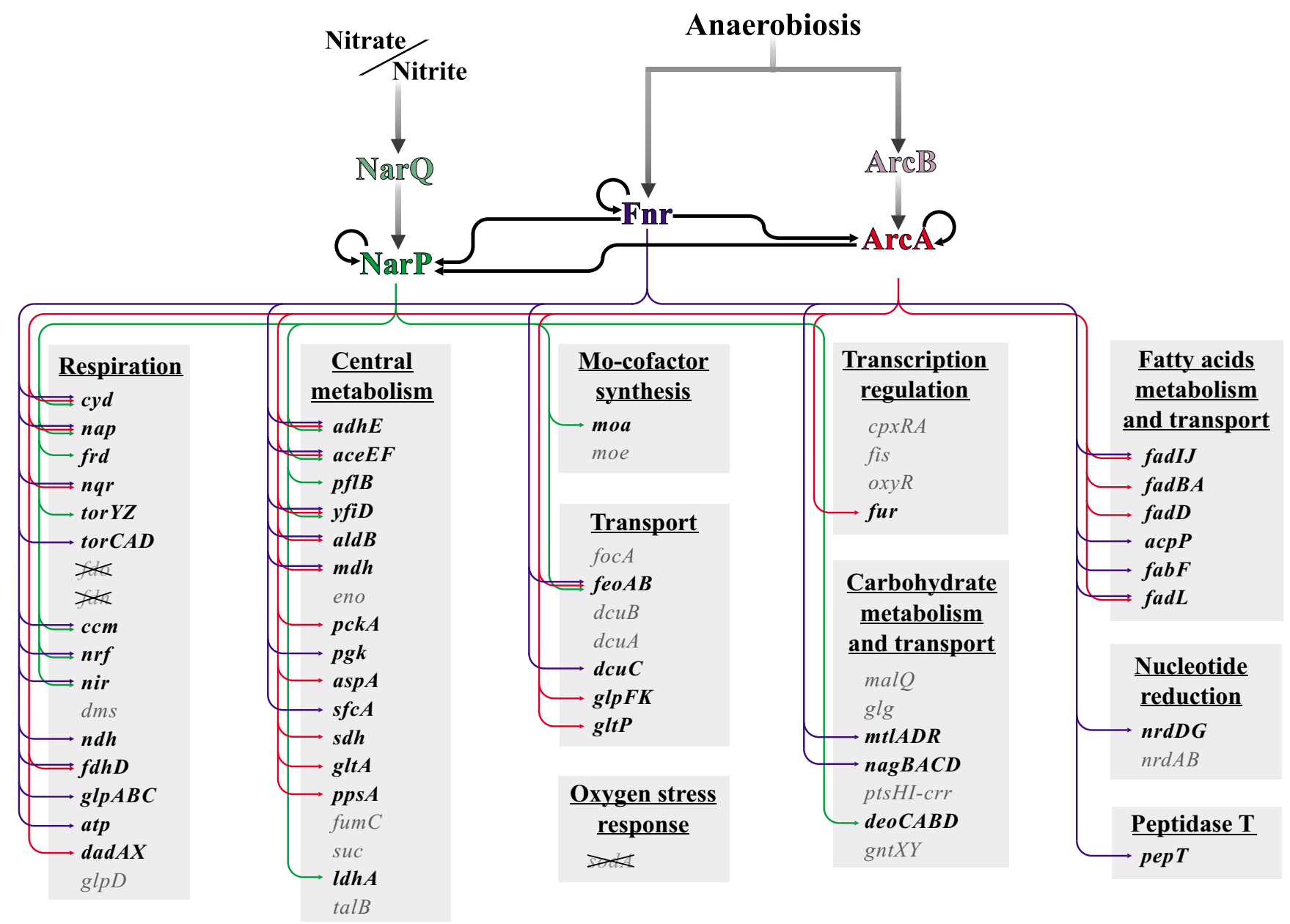

Figure 5

Regulatory interactions in Vibrionaceae. Notation as in Figure 3.

A specific feature of the Pasteurellaceae is also the existence of downstream cascades, as several transcription factor-encoding genes, c $p x R A$, fis, oxyR and fur, are preceded by conserved candidate sites. All of these operons, except fur, have no candidate sites in other studied genomes. One possible explanation might be that drastic re-structuring of the regulatory cascades during evolution of the Pasteurellaceae required additional fine tuning of the respiratory metabolism.

The increased role of the NarP transcriptional factor in the regulatory cascades is consistent with the expansion of the NarP regulog (Figure 4). This expansion is realized in different ways. For example, upstream of the $c y d$ and $n q r$ operons, NarP sites emerged in addition to the existing Fnr and ArcA ones. In the case of the mdh, eno and suc operons, we observe a change in the regulatory interactions, where NarP candidate sites appear instead of Fnr of ArcA sites seen in other families. Finally, NarP sites upstream of the eno and talB genes appear in the Pasteurel- laceae, while there are no sites for the studied factors in other genomes.

\section{Vibrionaceae}

In these genomes, the Fnr role as the main regulator is conserved, but the role of the ArcA in the regulatory cascades slightly increases.

Again, this agrees with the expansion of the ArcA regulog, as there appear ArcA sites upstream of genes of central metabolism (Figure 5). Conserved candidate ArcA binding sites were also found upstream of other genes (additional file 4).

Ten analyzed representatives of gamma-proteobacteria occupy different ecological niches: $H$. ducreyi is an obligate pathogen [86], Y. pestis, Y. enterocolitica, P. multocida, $A$. actinomycetemcomitans, $H$. influenzae, $V$. vulnificus, $V$. parahaemolyticus and $V$. cholerae are facultative pathogens [87-94], and V. fischeri is a squid symbiont [95]. However, 
there are no obvious links between the bacterial lifestyle and specific regulatory interactions or regulog composition.

\section{Variability of the nitrate and nitrite responsive regulatory system}

Comparison of three global transcription regulators, Fnr, ArcA and NarP, demonstrates that the NarP-dependent regulation is the most flexible.

As we could not construct a NarL-site recognition rule, we considered only genomes containing NarP but not NarL. In all these genomes, the cytoplasmic nitrate respiratory system is absent and all reactions for the reduction of nitrate through nitrite to ammonium must occur in the periplasm. For this purpose, the proteins encoded by nap, $\mathrm{ccm}$ and $n r f$ are sufficient. On the other hand, the genes for the cytoplasmic nitrate reduction, narGHJI and narK, are absent. In some studied genomes, the Yersinia spp. and most of the Vibrionaceae, the nir operon also is conserved [24]. This operon is used for the cytoplasmic nitrite reduction to ammonium, neutralizing toxic nitrite and providing ammonium as a substrate for the nitrogen assimilation [2]. Without the use of the cytoplasmic nitrite reduction, there is no need to select between the more effective, but also more dangerous, nitrate reduction in the cytoplasm, and the less effective but safer periplasmic reduction. Thus, all studied organisms do not require duplicated two-component regulatory systems and use the single pair NarP-NarQ.

In the Yersinia spp., an unusual sensor-regulator pair, NarX-NarP, was observed (additional file 7) [24]. However, in these genomes the sensor protein lacks the cysteine cluster typical for NarX from other species $[23,24]$. Thus, we can suppose that NarX from Yersinia spp. acts as NarQ.

Another interesting result was the observation of conserved candidate NarP sites upstream of genes for aerobic respiration, glycolysis/gluconeogenesis and citrate cycle, $m d h$, eno, pgk, sucABCD and $n q r$ in Pasteurellaceae, and $c \gamma d A B$ in the Pasteurellaceae and the Vibrionaceae. Regulation of genes for the aerobic metabolism by NarQ-NarP system may be explained by the fact that the NarQ sensor protein is sensitive to aeration [96].

\section{Conclusion}

Previously the regulation of respiration in the gammaproteobacteria was well studied only in Escherichia coli and two experimental approaches prevailed. The first one was studying the regulation of a particular operon by multiple factors. The second approach was the analysis of multiple genes controlled by a specific regulatory system in one genome. With sequencing of complete genomes and development of comparative genomic methods, extensive analysis of a complex regulatory system in multiple genomes has become possible.

Here we applied a comparative genomic technique to the analysis of global regulation of respiration in numerous gamma-proteobacterial genomes. We analyzed three structurally different but functionally related regulatory systems.

One of the advantages of the applied technique is the possibility to study genomes for which no experimental data are available. It also allows one to find new members of regulons and to detect taxon-specific features of regulation. Thus, the saturation of the taxonomic space by complete genome sequences increases the opportunities for the application of comparative genomics.

In this article and supplementary materials we present the data about candidate sites, both conserved and non-conserved, in multiple genomes. These data are interesting from the point of view of evolution and also may be of use for experimental biology. At that, prediction of the specific sites upstream of particular operons facilitates the work of experimentalist in finding new members of regulons.

In the particular case of the respiration regulation, we were able to predict not only taxon-specific members of regulons, but also taxon-specific changes in regulatory cascades. We demonstrated considerable changes of regulatory interactions in different families and relative stability of the metabolic and regulatory systems taken as a whole. Similar observations were made in studies of dissimilatory metabolism of nitrogen oxides [97], iron homeostasis [98] and nitrogen fixation (work in progress). Overall, existence of a stable system core, rewiring of regulatory cascades accompanied by shuffling of the regulators, and existence of taxon-specific periphery seem to be common features of all complex regulatory systems. At present, it is not clear what drives these changes. We have observed a correlation between the regulon size and the position of a regulator in regulatory cascades: regulators with larger regulons tend to occupy top positions in cascaeds, and thus re-wiring of cascades is accompanied with extension of regulons. On the other hand, there is no obvious link to differences in the species' lifestyles, metabolic capabilities, etc.

\section{Methods \\ Genomes}

Respiration was studied in ten genomes of organisms from three bacterial families: 
Enterobacteriaceae (Yersinia pestis KIM, YP; Yersinia enterocolitica type 0:8, YE), Pasteurellaceae (Pasteurella multocida Pm70, PM; Actinobacillus actinomycetemcomitans HK1651, AA; Haemophilus influenzae Rd, HI; Haemophilus ducreyi $35000 \mathrm{H}, \mathrm{HD})$, and Vibrionaceae (Vibrio vulnificus CMCP6, VV; Vibrio parahaemolyticus RIMD 2210633, VP; Vibrio cholerae O1, VC; Vibrio fischeri ES114, VF). All studied organisms contain FNR, ArcA and NarP, but lack NarL.

The complete genome sequences of Y. pestis [99], P. multocida [100], H. influenzae [101], H. ducreyi [GenBank:AE017143], V. vulnificus [102], V. parahaemolyticus [103], V. cholerae [104], and V. fischeri [105] were downloaded from the GenBank database [106]. The complete sequence of $Y$. enterocolitica was taken from the Sanger Institute web site [107]. The complete sequence of $A$. actinomycetemcomitans was taken from the University of Oklahoma's Advanced Center for Genome Technology web site [108].

\section{Comparative genomics of family-specific regulation}

To describe three interacting regulatory systems, comparative genomic approaches were used [109]. Candidate sites were identified in upstream regions of annotated genes, including hypothetical ones. A gene was considered a putative member of a regulog (a group of regulated orthologs) [110], if it had an upstream candidate site in several genomes. Site search was performed in gene upstream regions, -500 to +100 nucleotides relative to the gene start, excluding coding regions of upstream genes. The recognition profiles (nucleotide weight matrices) [109] for Fnr [27], ArcA [28] and NarP [24] were described previously. The recognition profiles and sequence logos are shown in additional files 8 and 9, respectively.

The cutoff profile scores for ArcA and FNR sites were set using known E. coli sites from the dpinteract database [111]. All E. coli FNR-binding sites passed the threshold 3.75, and all E. coli ArcA binding sites, but one outlier (upstream of the gene $p f l A$ ), scored above the used threshold 4.00. With these parameters about 600 genes per genome had candidate sites in upstream regions. The cutoff for candidate NarP binding sites (3.50) was defined as the minimum score of candidate NarP sites upstream of the nitrate and nitrite respiration genes (nap, nrf and $\mathrm{ccm}$ ) in all studied genomes. This cutoff produced about 300 genes per genome.

Clearly, most candidate sites at this stage were false positives, but the threshold could not be made stricter without loss of true sites. Anyhow, after the filtration procedure described below the number of candidate regulog members significantly decreased. Only few genes with no obvious functional link to the studied systems remained, and in most cases this was caused by sites occurring upstream of divergently transcribed genes. These observations demonstrate that the filtration procedure seems to be sufficiently effective to remove most false positives. On the other hand, each individual prediction should be considered as preliminary. Another caveat is that "orphan" sites (species-specific sites upstream of genes not regulated by other considered factors) cannot be identified by the applied procedure.

Possible operon structure was taken into account as follows. Genes were assumed to belong to one operon if (i) they were transcribed in the same direction, (ii) the intergenic distances did not exceed 200 nucleotides, and (iii) two previous conditions were met in genomes from different families. These conditions are known to perform well in operon prediction [111].

As the regulation of respiration had not been experimentally analyzed in any of the studied organisms, we developed a technique based on exhaustive pairwise comparison of genomes within taxonomic groups. For the Pasteurellaceae and the Vibrionaceae, a gene was assigned to a regulog if candidate regulatory sites were found upstream of an operon containing this gene in at least three genomes of organisms from the same family. For the Yersinia spp., a gene was considered to be a member of a regulog if candidate sites were found in both $Y$. pestis and $Y$. enterocolitica genomes. Such sites were called "conserved sites". Sites that did not satisfy these requirements were called "nonconserved". Further, if a site for one regulator was found upstream of a particular gene in one taxon, we searched for sites for all three regulators upstream of this gene and its orthologs in all studied genomes.

This approach allowed us to find new members of regulogs and to describe taxon-specific features of regulation. Its limitation is that it allows one to detect only the fact of regulation but, due to the absence of mapped promoters in the studied genomes, does not predict the type of regulation, such as repression or activation.

\section{Programs}

The search for candidate sites was done using Genome Explorer [112]. Orthologs were determined as pairs of best bi-directional hits [113] identified by Genome Explorer [112]. Multiple sequence alignments and phylogenetic trees were done using ClustalX [114]. Search for homologs of studied genes in sequence databases was done using the BLAST program [115] with E-value cutoff $e^{-20}$.

\section{Authors' contributions}

AAM and MSG designed and coordinated the project. DAR and AVG carried out the genome analysis. DAR and 
MSG drafted the manuscript. All authors have read and approved the final manuscript.

\section{Additional material}

\section{Additional File 1}

Predicted regulatory interactions. For genome abbreviations see "Methods". Candidate sites are shown by letters: F - Fnr sites; A - ArcA sites, $N-N a r P$ sites; conserved sites are shown by capital letters, non-conserved ones by lower-case letters (for details see "Methods"). Absence of sites is shown by dashes. Absent genes are shown by zeros. Cases when the operon structure is not conserved are denoted by superscripts, and the structures of the corresponding operons are described in detail in additional file 2 using the matching superscripts.

Click here for file

[http://www.biomedcentral.com/content/supplementary/14712164-8-54-S1.pdf]

\section{Additional File 2}

Observed changes in the operon structures. For genome abbreviations see "Methods". The superscripts correspond to the superscripts in additional file 1.

Click here for file

[http://www.biomedcentral.com/content/supplementary/14712164-8-54-S2.pdf]

\section{Additional File 3}

Phylogenetic trees for FdnG/FdoG (a), FdnH/FdoH (b) and FdnI/FdoI. The trees were constructed by the neighbour-joining method. The expected fraction of amino acid substitutions is indicated for branches longer than 0.05. Genome abbreviations: EC - Escherichia coli, ST - Salmonella typhi, EO - Erwinia carotovora, YP - Yersinia pestis, YE - Y. enterocolitica, $P M$ - Pasteurella multocida, AA - Actinobacillus actinomycetemcomitans, HI-Haemophilus influenzae. The analysis of the trees indicates that the most parsimonious evolutionary scenario is the duplication of the fumarate dehydrogenase operon in the ancestral Enterobacteria and further species-specific loss of the Fdn copy in the Yersinia lineage. In any case, it is clear that the fumarate dehydrogenase of the Yersinia spp. is Fdo.

Click here for file

[http://www.biomedcentral.com/content/supplementary/14712164-8-54-S3.pdf]

\section{Additional File 4}

Additional predicted regulatory interactions. "For genome abbreviations see "Methods". Candidate sites are shown by letters: F - Fnr sites, A ArcA sites, N - NarP sites; conserved sites are shown by capital letters, non-conserved ones, by lower-case letters (for details see "Methods"). Absence of the corresponding sites is shown by dashes. Absent genes are shown by zeros. Superscripts point to changes in operon structures described in detail in additional file 5. \#: operon forms a divergon with an another one."

Click here for file

[http://www.biomedcentral.com/content/supplementary/14712164-8-54-S4.pdf]

\section{Additional File 5}

Additional observed changes in the operon structures. For genome abbreviations see "Methods". Superscripts coincide with the corresponding superscripts in additional file 4.

Click here for file

[http://www.biomedcentral.com/content/supplementary/14712164-8-54-S5.pdf]

\section{Additional File 6}

False-positive predictions. The last column lists the reasons to exclude the operons. For genome abbreviations see "Methods".

Click here for file

[http://www.biomedcentral.com/content/supplementary/1471-

2164-8-54-S6.pdf]

\section{Additional File 7}

Phylogenetic trees for NarL/NarP (a) and NarX/NarQ (b). The trees were constructed by the neighbour-joining method. The expected fraction of amino acid substitutions is indicated for brances. The branches corresponding to Yersinia spp. proteins are shown with broken lines. Genome abbreviations: EC - Escherichia coli, ST - Salmonella typhi, EO Erwinia carotovora, $Y P$ - Yersinia pestis, $Y E-Y$. enterocolitica, $P M$ - Pasteurella multocida, AA - Actinobacillus actinomycetemcomitans, HI - Haemophilus influenzae, HD - Haemophilus ducreyi, $V V$ - Vibrio vulnificus, $V P-V$. parahaemolyticus, $V C-V$. cholerae, $V F$ - Vibrio fischeri

Click here for file

[http://www.biomedcentral.com/content/supplementary/14712164-8-54-S7.pdf]

\section{Additional File 8}

Position weight matrices (profiles) for Fnr (a), ArcA (b) and NarP (c) binding sites. Rows: nucleotides. Columns: Positions. Cells: positional nucleotide weights.

Click here for file

[http://www.biomedcentral.com/content/supplementary/1471-

2164-8-54-S8.pdf]

\section{Additional File 9}

Sequence logos for the Fnr (a), ArcA (b) and NarP (c) binding sites. Horizontal axis, position in the binding site; vertical axis, information content in bits. The height of each column is proportional to the positional information content in the given position; the height of each individual symbol reflects its prevalence in the given position.

Click here for file

[http://www.biomedcentral.com/content/supplementary/1471-

2164-8-54-S9.pdf]

\section{Acknowledgements}

We are grateful to Alexandra B. Rakhmaninova, Alexander Favorov, Olga Laikova and Dmitry Rodionov for useful discussions.

This study was supported by grants from the Howard Hughes Medical Institute (550056 10), the Russian Academy of Science (Program "Molecular and Cellular Biology"), the Russian Foundation for Basic Research (04-044936I), and INTAS (05-8028).

\section{References}

I. Unden G, Bongaerts J: Alternative respiratory pathways of Escherichia coli: energetics and transcriptional regulation in response to electron acceptors. Biochim Biophys Acta 1997, 1320:217-234.

2. Gennis RB, Stewart V: Respiration. In Escherichia coli and Salmonella. Cellular and Molecular Biology I Edited by: Neidhart FC. Washington: ASM Press; 1996:217-286.

3. Lazazzera BA, Beinert H, Khoroshilova N, Kennedy MC, Kiley PJ: DNA binding and dimerization of the Fe-S-containing FNR protein from Escherichia coli are regulated by oxygen. J Biol Chem 1996, 27:2762-2768. 
4. Kiley PJ, Beinert $\mathrm{H}$ : Oxygen sensing by the global regulator FNR: the role of the iron-sulfur cluster. FEMS Microbiol Rev 1999, 22:34I-352.

5. Lynch AS, Lin CC: Responses to molecular oxygen. In Escherichia coli and Salmonella. Cellular and Molecular Biology I Edited by: Neidhart FC. Washington: ASM Press; 1996:1526-1537.

6. Takahashi K, Hattori T, Nakanishi T, Nohno T, Fujita N, Ishihama A, Taniguchi S: Repression of in vitro transcription of the Escherichia coli fnr and narX genes by FNR protein. FEBS Lett 1996, 340:59-64.

7. Compan I, Touati D: Anaerobic activation of arcA transcription in Escherichia coli: roles of Fnr and ArcA. Mol Microbiol 1994, I I:955-964.

8. Georgellis D, Kwon O, Lin EC: Quinones as the redox signal for the arc two-component system of bacteria. Science 200I, 292:23।4-2316.

9. Malpica R, Franco B, Rodriguez C, Kwon O, Georgellis D: Identification of a quinone-sensitive redox switch in the $A r c B$ sensor kinase. Proc Natl Acad Sci USA 2004, I 0 I: I I 3 | 8- | | 323.

10. Toro-Roman A, Mack TR, Stock AM: Structural analysis and solution studies of the activated regulatory domain of the response regulator ArcA: a symmetric dimer mediated by the alpha4-beta5-alpha5 face. I Mol Biol 2005, 349: I I-26.

II. Jeon Y, Lee YS, Han JS, Kim JB, Hwang DS: Multimerization of phosphorylated and non-phosphorylated ArcA is necessary for the response regulator function of the Arc two-component signal transduction system. I Biol Chem 200I, 276:40873-40879.

12. Lynch AS, Lin EC: Transcriptional control mediated by the ArcA two-component response regulator protein of Escherichia coli: characterization of DNA binding at target promoters. J Bacteriol 1996, 178:6238-6249.

13. luchi S, Lin EC: arcA (dye), a global regulatory gene in Escherichia coli mediating repression of enzymes in aerobic pathways. Proc Natl Acad Sci USA 1988, 85: $1888-1892$.

14. Unden G, Becker S, Bongaerts J, Holighaus G, Schirawski J, Six S: $\mathbf{O}_{2}$ sensing and $\mathrm{O}_{2}$-dependent gene regulation in facultatively anaerobic bacteria. Arch Microbiol 1995, 164:81-90.

15. Darwin AJ, Tyson KL, Busby S], Stewart V: Differential regulation by the homologous response regulators $\mathrm{NarL}$ and $\mathrm{NarP}$ of Escherichia coli K-1 2 depends on DNA binding site arrangement. Mol Microbiol 1997, 25:583-595.

16. Rabin RS, Stewart V: Dual response regulators (NarL and NarP) interact with dual sensors (NarX and NarQ) to control nitrate- and nitrite-regulated gene expression in Escherichia coli K-I 2. J Bacteriol 1993, 175:3259-3268.

17. Williams SB, Stewart V: Discrimination between structurally related ligands nitrate and nitrite controls autokinase activity of the NarX transmembrane signal transducer of Escherichia coli K-12. Mol Microbiol 1997, 26:91 I-925.

18. Chiang RC, Cavicchioli R, Gunsalus RP: 'Locked-on' and 'lockedoff signal transduction mutations in the periplasmic domain of the Escherichia coli NarQ and NarX sensors affect nitrateand nitrite-dependent regulation by NarL and NarP. Mol Microbiol 1997, 24: 1049-1060.

19. Darwin $\mathrm{A} J, \mathrm{Li}]$, Stewart $\mathrm{V}$ : Analysis of nitrate regulatory protein NarL-binding sites in the fdnG and narG operon control regions of Escherichia coli K-12. Mol Microbiol 1996, 20:62 I-632.

20. Li J, Kustu S, Stewart V: In vitro interaction of nitrate-responsive regulatory protein NarL with DNA target sequences in the fdnG, narG, narK and frdA operon control regions of Escherichia coli K-I2. J Mol Biol I994, 24 I: I50-165.

21. Stewart V, Bledsoe PJ: Synthetic lac operator substitutions for studying the nitrate- and nitrite-responsive NarX-NarL and NarQ-NarP two-component regulatory systems of Escherichia coli K-12. J Bacteriol 2003, 185:2104-2III.

22. Stewart $\mathrm{V}$ : Nitrate respiration in relation to facultative metabolism in enterobacteria. Microbiol Rev 1988, 52:190-232.

23. Stewart V: Biochemical society special lecture. Nitrate- and nitrite-responsive sensors NarX and NarQ of proteobacteria. Biochem Soc Trans 2003, 31:1-10.

24. Ravcheev DA, Rakhmaninova AB, Mironov AA, Gelfand MS: Regulation of nitrate and nitrite respiration in gammaproteobacteria: a comparative genomics study. Mol Biol (Mosk) 2005, 39:832-846.
25. Stewart V, Bledsoe PJ: Fnr-, NarP- and NarL-dependent regulation of transcription initiation from the Haemophilus influenzae Rd napF(Periplasmic Nitrate Reductase). J Bacteriol 2005, 187:6928-6935.

26. Raghunathan A, Price ND, Galperin MY, Makarova KS, Purvine S, Picone AF, Cherny T, Xie T, Reilly TJ, Munson RJr, Tyler RE, Akerley BJ, Smith AL, Palsson BO, Kolker E: In silico metabolic model and protein expression of Haemophilus influenzae strain Rd KW20 in rich medium. OMICS 2004, 8:25-4I.

27. Gerasimova AV, Rodionov DA, Mironov AA, Gel'fand MS: Computer analysis of regulatory signals in bacterial genomes. Fnr binding segments. Mol Biol (Mosk) 200I, 35:100I-1009.

28. Favorov AV, Gelfand MS, Gerasimova AV, Ravcheev DA, Mironov AA, Makeev VJ: A Gibbs sampler for identification of symmetrically structured, spaced DNA motifs with improved estimation of the signal length. Bioinformatics 2005, 21 :2240-2245.

29. Baikalov I, Schroder I, Kaczor-Grzeskowiak M, Grzeskowiak K, Gunsalus RP, Dickerson RE: Structure of the Escherichia coli response regulator NarL. Biochemistry 1996, 35: I 1053-I I 06 I.

30. Baikalov I, Schroder I, Kaczor-Grzeskowiak M, Cascio D, Gunsalus RP, Dickerson RE: NarL dimerization? Suggestive evidence from a new crystal form. Biochemistry 1998, 37:3665-3676.

31. Maris AE, Sawaya MR, Kaczor-Grzeskowiak M, Jarvis MR, Bearson SM, Kopka ML, Schroder I, Gunsalus RP, Dickerson RE: Dimerization allows DNA target site recognition by the NarL response regulator. Nat Struct Biol 2002, 9:77I-778.

32. Xiao G, Cole DL, Gunsalus RP, Sigman DS, Chen CH: Site-specific DNA cleavage of synthetic NarL sites by an engineered Escherichia coli NarL protein-I, I0-phenanthroline cleaving agent. Protein Sci 2002, I 2:2427-2436.

33. Gerasimova AV, Gelfand MS, Makeev VY, Mironov AA, Favorov AV: ArcA regulator of gamma-proteobacteria: Identification of the binding signal and description of the regulon. Biophysics 2003, 48:2I-25.

34. Nielsen J, Jorgensen BB, van Meyenburg KV, Hansen FG: The promoters of the atp operon of Escherichia coli K I 2. Mol Gen Genet |984, | 193:64-7|.

35. Kasimoglu E, Park SJ, Malek J, Tseng CP, Gunsalus RP: Transcriptional regulation of the proton-translocating ATPase (atpIBEFHAGDC) operon of Escherichia coli: control by cell growth rate. J Bacteriol 1996, I 78:5563-5567.

36. Salmon K, Hung SP, Mekjian K, Baldi P, Hatfield GW: Global gene expression profiling in Escherichia coli $\mathrm{KI}$. The effects of oxygen availability and FNR. J Biol Chem 2003, 278:29837-29855.

37. Salmon KA, Hung SP, Steffan NR, Krupp R, Baldi P, Hatfield GW, Gunsalus RP: Global gene expression profiling in Escherichia coli KI 2: The effects of oxygen availability and ArcA. J Biol Chem 2005, 280: I 5084-I5096.

38. Beattie P, Tan K, Bourne RM, Leach D, Rich PR, Ward FB: Cloning and sequencing of four structural genes for the $\mathrm{Na}^{+}$-translocating NADH-ubiquinone oxidoreductase of Vibrio alginolyticus. FEBS Lett 1994, 356:333-338.

39. Hase CC, Mekalanos J]: Effects of changes in membrane sodium flux on virulence gene expression in Vibrio cholerae. Proc Nat Acad Sci USA 1999, 96:3183-3187.

40. Hayashi M, Nakayama $Y$, Unemoto $T$ : Recent progress in the $\mathrm{Na}(+)$-translocating $\mathrm{NADH}$-quinone reductase from the marine Vibrio alginolyticus. Biochim Biophys Acta 200I, I 505:37-44.

4I. Hayashi M, Hirai K, Unemoto T: Sequencing and the alignment of structural genes in the nqr operon encoding the $\mathrm{Na}(+)$ translocating NADH-quinone reductase from Vibrio alginolyticus. FEBS Lett 1995, 363:75-77.

42. Hayashi M, Nakayama Y, Unemoto T: Existence of Nat-translocating NADH-quinone reductase in Haemophilus influenzae. FEBS Lett 1996, 381:174-176.

43. Bertsova YV, Bogachev AV: The origin of the sodium-dependent NADH oxidation by the respiratory chain of Klebsiella pneumoniae. FEBS Lett 2004, 563:207-212.

44. Bongaerts J, Zoske S, Weidner U, Unden G: Transcriptional regulation of the proton translocating NADH dehydrogenase genes (nuoA-N) of Escherichia coli by electron acceptors, electron donors and gene regulator. Mol Microbiol 1995 , 16:521-534

45. Stolpe S, Friedrich T: The Escherichia coli NADH:ubiquinone oxidoreductase (complex I) is a primary proton pump but 
may be capable of secondary sodium antiport. I Biol Chem 2004, 279: I8377-18383.

46. Lobocka M, Hennig J, Wild J, Klopotowski T: Organization and expression of the Escherichia coli K- 12 dad operon encoding the smaller subunit of $D$-amino acid dehydrogenase and the catabolic alanine racemase. J Bacteriol 1994, 176:1500-1510.

47. Gon S, Patte JC, Mejean V, lobbi-Nivol C: The torYZ (yecK-bisZ) operon encodes a third respiratory trimethylamine $\mathbf{N}$-oxide reductase in Escherichia coli. J Bacteriol 2000, 182:5779-5786.

48. Mejean V, lobbi-Nivol C, Lepelletier M, Giordano G, Chippaux M, Pascal MC: TMAO anaerobic respiration in Escherichia coli: involvement of the tor operon. Mol Microbiol 1994, II:II69-II79.

49. luchi S, Lin EC: The narL gene product activates the nitrate reductase operon and represses the fumarate reductase and trimethylamine $\mathbf{N}$-oxide reductase operons in Escherichia coli. Proc Natl Acad Sci USA 1987, 84:390 I-3905.

50. Simon G, Mejean V, Jourlin C, Chippaux M, Pascal MC: The torR gene of Escherichia coli encodes a response regulator protein involved in the expression of the trimethylamine $\mathbf{N}$-oxide reductase genes. J Bacteriol 1994, I 76:560I-5606.

51. Wang H, Gunsalus RP: Coordinate regulation of the Escherichia coli formate dehydrogenase $\mathrm{fdnGHI}$ and $\mathrm{fdhF}$ genes in response to nitrate, nitrite, and formate: roles for NarL and NarP. J Bacteriol 2003, 185:5076-5085.

52. Li J, Stewart V: Localization of upstream sequence elements required for nitrate and anaerobic induction of $f d n$ (formate dehydrogenase-N) operon expression in Escherichia coli K12. I Bacteriol 1992, 174:4935-4942.

53. Abaibou H, Pommier J, Benoit S, Giordano G, Mandrand-Berthelot MA: Expression and characterization of the Escherichia coli fdo locus and a possible physiological role for aerobic formate dehydrogenase. J Bacteriol 1995, 177:7|4I-7I49.

54. Schlindwein C, Giordano G, Santini CL, Mandrand MA: Identification and expression of the Escherichia coli fdhD and fdhE genes, which are involved in the formation of respiratory formate dehydrogenase. J Bacteriol |990, |72:6| |2-6|2|.

55. Shalel-Levanon S, San KY, Bennett GN: Effect of oxygen, and ArcA and FNR regulators on the expression of genes related to the electron transfer chain and the TCA cycle in Escherichia coli. Metab Eng 2005.

56. Shalel-Levanon S, San KY, Bennett GN: Effect of ArcA and FNR on the expression of genes related to the oxygen regulation and the glycolysis pathway in Escherichia coli under microaerobic growth conditions. Biotechnol Bioeng 2005, 92: I47-I59.

57. Saier MH, Ramseier TM, Reizer J: Regulation of carbon utilization. In Escherichia coli and Salmonella. Cellular and Molecular Biology. Edited by: Neidhart FC. Washington: ASM Press; 1996: I325-1333.

58. Postma PW, Lengeler JW, Jacobson GR: Phosphoenolpyruvate:carbohydrate phosphotransferase systems. In Escherichia coli and Salmonella. Cellular and molecular biology Edited by: Neidhardt FC. Washington: ASM Press; 1996: I 149-1 I74.

59. Neughard J, Kelln RA: Biosynthesis and conversions of pyrimidines. In Escherichia coli and Salmonella. Cellular and molecular biology. I Edited by: Neidhardt FC. Washington: ASM Press; 1990:580-599.

60. Plumbridge JA, Cochet O, Souza JM, Altamirano MM, Calcagno ML, Badet $B$ : Coordinated regulation of amino sugar-synthesizing and -degrading enzymes in Escherichia coli K-12. J Bacterio 1993, 175:495|-4956.

61. Porco A, Alonso G, Isturiz T: The gluconate high affinity transport of Gntl in Escherichia coli involves a multicomponent complex system. J Basic Microbiol I998, 38:395-404.

62. Decker K, Peist R, Reidl J, Kossmann M, Brand B, Boos W: Maltose and maltotriose can be formed endogenously in Escherichio coli from glucose and glucose-I-phosphate independently of enzymes of the maltose system. J Bacteriol 1993, 175:5655-5665.

63. Yang H, Liu MY, Romeo T: Coordinate genetic regulation of glycogen catabolism and biosynthesis in Escherichia coli via the CsrA gene product. J Bacteriol 1996, 178:1012-1017.

64. Campbell JW, Morgan-Kiss RM, Cronan JE: A new Escherichia coli metabolic competency: growth on fatty acids by a novel anaerobic beta-oxidation pathway. Mol Microbiol 2003 , 47:793-805.

65. Clark DP, Cronan JE: Two-carbon compounds and fatty acids as carbon sources. In Escherichia coli and Salmonella. Cellular and Molec- ular Biology. I Edited by: Neidhart FC. Washington: ASM Press; 1996:343-357.

66. Cronan JE, Rock CO: Biosynthesis of membrane lipids. In Escherichia coli and Salmonella. Cellular and molecular biology. I Edited by: Neidhardt FC. Washington: ASM Press; 1996:612-636.

67. Lin ECC: Amino acids as carbon sources. In Escherichia coli and Salmonella. Cellular and molecular biology. I Edited by: Neidhardt FC. Washington: ASM Press; 1996:358-379.

68. Boston T, Atlung T: FNR-mediated oxygen-responsive regulation of the nrdDG operon of Escherichia coli. J Bacteriol 2003, 185:5310-53|3.

69. Schneider R, Lurz R, Luder G, Tolksdorf C. Travers A, Muskhelishvili G: An architectural role of the Escherichia coli chromatin protein FIS in organising DNA. Nucleic Acids Res 2001, 29:5 I07-5II4.

70. Browning DF, Grainger DC, Beatty CM, Wolfe AJ, Cole JA, Busby SJ: Integration of three signals at the Escherichia coli nrf promoter: a role for Fis protein in catabolite repression. Mol Microbiol 2005, 57:496-5 I0

7I. Browning DF, Cole JA, Busby S): Transcription activation by remodelling of a nucleoprotein assembly: the role of $\mathrm{NarL}$ at the FNR-dependent Escherichia coli nir promoter. Mol Microbiol 2004, 53:203-2I5.

72. Jackson L, Blake T, Green J: Regulation of ndh expression in Escherichia coli by Fis. Microbiology 2004, I 50:407-4I3.

73. Membrillo-Hernandez J, Lin EC: Regulation of expression of the adhE gene, encoding ethanol oxidoreductase in Escherichia coli: transcription from a downstream promoter and regulation by fnr and RpoS. J Bacteriol 1999, I 81:757|-7579.

74. Green J, Baldwin ML, Richardson J: Downregulation of Escherichia coli yfiD expression by FNR occupying a site at $\mathbf{- 9 3 . 5}$ involves the ARI-containing face of FNR. Mol Microbiol 1998, 29: III3-II 23.

75. Cunningham L, Guest JR: Transcription and transcript processing in the sdhCDAB-sucABCD operon of Escherichia coli. Microbiology 1998, I44:2II3-2I23.

76. Cunningham L, Gruer MJ, Guest JR: Transcriptional regulation of the aconitase genes (acnA and $a \operatorname{cn} B)$ of Escherichia coli. Microbiology I997, I43:3795-3805.

77. Kolesnikow T, Schroder I, Gunsalus RP: Regulation of narK gene expression in Escherichia coli in response to anaerobiosis, nitrate, iron, and molybdenum. I Bacteriol 1992, 174:7I04-7I0II.

78. Ninnemann O, Koch C, Kahmann R: The E.coli fis promoter is subject to stringent control and autoregulation. $E M B O J \mid 992$, I I: 1075-1083.

79. Raivio TL: Envelope stress responses and Gram-negative bacterial pathogenesis. Mol Microbiol 2005, 56: I I 19-I I 28.

80. luchi S, Furlong D, Lin EC: Differentiation of $\operatorname{arcA}$, $\operatorname{arcB}$, and $c p \times A$ mutant phenotypes of Escherichia coli by sex pilus formation and enzyme regulation. I Bacteriol | 989, I 7 I:2889-2893.

81. Christman MF, Storz G, Ames BN: OxyR, a positive regulator of hydrogen peroxide-inducible genes in Escherichia coli and Salmonella typhimurium, is homologous to a family of bacterial regulatory proteins. Proc Natl Acad Sci USA 1989 , 86:3484-3488.

82. Bagg A, Neilands JB: Ferric uptake regulation protein acts as a repressor, employing iron (II) as a cofactor to bind the operator of an iron transport operon in Escherichia coli. Biochemistry 1987, 26:547।-5477.

83. Sutton VR, Mettert EL, Beinert H, Kiley PJ: Kinetic analysis of the oxidative conversion of the $[4 \mathrm{Fe}-4 \mathrm{~S}]^{2+}$ cluster of FNR to a $[2 \mathrm{Fe}-2 \mathrm{~S}]^{2+}$ cluster. J Bacteriol 2004, 1 86:80।8-8025.

84. Darwin Al, Stewart V: Expression of the narX, narL, narP, and narQ genes of Escherichia coli K-I 2: regulation of the regulators. J Bacteriol 1995, 177:3865-3869.

85. Gralnick JA, Brown CT, Newman DK: Anaerobic regulation by an atypical Arc system in Shewanella oneidensis. Mol Microbiol 2005, 56:1347-1357.

86. Wood GE, Dutro SM, Totten PA: Haemophilus ducreyi inhibits phagocytosis by U-937 cells, a human macrophage-like cell line. Infect Immun 200I, 69:4726-4733.

87. Sebbane F, Lemaitre N, Sturdevant DE, Rebeil R, Virtaneva K, Porcella SF, Hinnebusch BJ: Adaptive response of Yersinia pestis to extracellular effectors of innate immunity during bubonic plague. Proc Natl Acad Sci USA 2006, I 03: I 1766- I I77। I. 
88. Orth JH, Lang S, Aktories K: Action of Pasteurella multocida toxin depends on the helical domain of $\mathbf{G} \alpha_{\mathbf{q}}$. J Biol Chem 2004, 279:34I50-34I55

89. Rohde JR, Luan XS, Rohde H, Foxm JM, Minnich SA: The Yersinio enterocolitica pYV virulence plasmid contains multiple intrinsic DNA bends which melt at 37 degrees C. J Bacteriol |999, | 8 |:4198-4204.

90. de Haar SF, Hiemstra PS, van Steenbergen MT, Everts V, Beertsen W: Role of polymorphonuclear leukocyte-derived serine proteinases in defense against Actinobacillus actinomycetemcomitans. Infect Immun 2006, 9:5284-529I.

91. Bayliss CD, Sweetman WA, Moxon ER: Mutations in Haemophilus influenzae mismatch repair genes increase mutation rates of dinucleotide repeat tracts but not dinucleotide repeatdriven pilin phase variation rates. I Bacteriol 2004, I 86:2928-2935.

92. Amaro C, Biosca EG, Fouz B, Alcaide E, Esteve C: Evidence that water transmits Vibrio vulnificus biotype 2 infections to eels. Appl Environ Microbiol I995, 6 I: I I33-I I37.

93. Sizemore RK, Colwell RR, Tubiash HS, Lovelace TE: Bacterial flora of the hemolymph of the blue crab, Callinectes sapidus: numerical taxonomy. Appl Environ Microbiol 1975, 29:393-399.

94. Rivera IN, Chun J, Huq A, Sack RB, Colwell RR: Genotypes associated with virulence in environmental isolates of Vibrio cholerae. Appl Environ Microbiol 2001, 67:2421-2429.

95. Nyholm SV, McFall-Ngai MJ: The winnowing: establishing the squid-vibrio symbiosis. Nat Rev Microbial 2004, 2:632-642.

96. Stewart V, Chen LL, Wu HC: Response to culture aeration mediated by the nitrate and nitrite sensor NarQ of Escherichia coli K-I2. Mol Microbiol 2003, 50:I39|-I399.

97. Rodionov DA, Dubchak IL, Arkin AP, Alm EJ, Gelfand MS: Dissimilatory metabolism of nitrogen oxides in bacteria: comparative reconstruction of transcriptional networks. PLOS Comput Biol 2005, I:e55.

98. Rodionov DA, Gelfand MS, Todd JD, Curson AR, Johnston AW: Comparative reconstruction of transcriptional network controlling iron and manganese homeostasis in alpha-proteobacteria. PLOS Comput Biol 2006, 2:el63.

99. Deng W, Burland V, Plunkett G, Boutin A, Mayhew GF, Liss P, Perna NT, Rose DJ, Mau B, Zhou S, Schwartz DC, Fetherston JD, Lindler LE, Brubaker RR, Plano GV, Straley SC, McDonough KA, Nilles ML, Matson JS, Blattner FR, Perry RD: Genome sequence of Yersinia pestis KIM. J Bacteriol 2002, I 84:460 I-46II.

100. May BJ, Zhang Q, Li LL, Paustian ML, Whittam TS, Kapur V: Complete genomic sequence of Pasteurella multocida, Pm70. Proc Natl Acad Sci USA 200I, 98:3460-3465.

I0I. Fleischmann RD, Adams MD, White O, Clayton RA, Kirkness EF, Kerlavage AR, Bult CJ, Tomb JF, Dougherty BA, Merrick JM, McKenney K, Sutton GG, FitzHugh W, Fields CA, Gocayne JD, Scott JD, Shirley R, Liu LI, Glodek A, Kelley JM, Weidman JF, Phillips CA, Spriggs T, Hedblom E, Cotton MD, Utterback T, Hanna MC, Nguyen DT, Saudek DM, Brandon RC, Fine LD, Fritchman JL, Fuhrmann JL, Geoghagen NS, Gnehm CL, McDonald LA, Small KV, Fraser CM, Smith HO, Venter JC: Whole-genome random sequencing and assembly of Haemophilus influenzae Rd. Science 1995, 269:496-5I 2.

102. Kim YR, Lee SE, Kim CM, Kim SY, Shin EK, Shin DH, Chung SS, Choy HE, Progulske-Fox A, Hillman JD, Handfield M, Rhee JH: Characterization and pathogenic significance of Vibrio vulnificus antigens preferentially expressed in septicemic patients. Infect Immun 2003, 71:546I-547I.

103. Makino K, Oshima K, Kurokawa K, Yokoyama K, Uda T, Tagomori K, lijima Y, Najima M, Nakano M, Yamashita A, Kubota YKSYT, Honda $T$, Shinagawa $H$, Hattori $M$, lida T: Genome sequence of Vibrio parahaemolyticus: a pathogenic mechanism distinct from that of V. cholerae. Lancet 2003, 36 I:743-749.

104. Heidelberg JF, Eisen JA, Nelson WC, Clayton RA, Gwinn ML, Dodson RJ, Haft DH, Hickey EK, Peterson JD, Umayam LA, Gill SR, Nelson KE, Read TD, Tettelin H, Richardson D, Ermolaeva MD, Vamathevan J, Bass S, Qin H, Dragoi I, Sellers P, McDonald L, Utterback T, Fleishmann RD, Nierman WC, White O, Salzberg SL, Smith HO, Colwell RR, Mekalanos JJ, Venter JC, Fraser CM: DNA sequence of both chromosomes of the cholera pathogen Vibrio cholerae. Nature 2000, 406:477-483.

105. Ruby EG, Urbanowski M, Campbell J, Dunn A, Faini M, Gunsalus R, Lostroh P, Lupp C, McCann J, Millikan D, Schaefer A, Stabb E, Stevens A, Visick K, Whistler C, Greenberg EP: Complete genome sequence of Vibrio fischeri: A symbiotic bacterium with pathogenic congeners. Proc Natl Acad Sci USA 2005, 102:3004-3009.

106. GenBank Overview [http://www.ncbi.nlm.nih.gov/Genbank]

107. The Wellcome Trust Sanger Institute [http:// www.sanger.ac.uk]

108. The University of Oklahoma's Advanced Center for Genome Technology [http://www.genome.ou.edu]

109. Gelfand MS, Koonin EV, Mironov AA: Prediction of transcription regulatory sites in Archaea by a comparative genomic approach. Nucleic Acids Res 2000, 28:695-705.

I10. Alkema WB, Lenhard B, Wasserman WW: Regulog analysis: detection of conserved regulatory networks across bacteria: application to Staphylococcus aureus. Genome Res 2004, 14:1362-1373.

III. DPInteract [http://arep.med.harvard.edu/dpinteract]

I 12. Mironov AA, Vinokurova NP, Gel'fand MS: Software for analyzing bacterial genomes. Mol Biol (Mosk) 2000, 34:253-262.

I 13. Tatusov RJ, Koonin EV, Lipman DJ: A genomic perspective on protein families. Science 1997, 278:63I-637.

I 14. Thompson JD, Gibson T], Plewniak F, Jeanmougin F, Higgins DG: The CLUSTAL_X windows interface: flexible strategies for multiple sequence alignment aided by quality analysis tools. Nucleic Acids Res 1997, 25:4876-4882.

I I5. Altschul SF, Madden TL, Schaffer AA, Zhang J, Zhang Z, Miller W, Lipman DJ: Gapped BLAST and PSI-BLAST: a new generation of protein database search programs. Nucleic Acids Res 1997 25:3389-3402.
Publish with Biomed Central and every scientist can read your work free of charge

"BioMed Central will be the most significant development for disseminating the results of biomedical research in our lifetime. "

Sir Paul Nurse, Cancer Research UK

Your research papers will be:

- available free of charge to the entire biomedical community

- peer reviewed and published immediately upon acceptance

- cited in PubMed and archived on PubMed Central

- yours - you keep the copyright
BioMedcentral 